\title{
Sociodramatic Play: Social Class Effects in Integrated Preschool Classrooms*
}

\author{
Greta G. Fein and Linda Stork \\ University of Michigan
}

\begin{abstract}
In previous studies, social class differences in children's sociodramatic play were studied in socially homogeneous, segregated schools. However, social class differences in play behavior were attributed to the abilities or interests of the children rather than to the situation in which they were observed. In the present study, sociodramatic play was observed in middle and lower class children attending the same preschool classrooms. In accord with previous studies, middle class children engaged in a higher level of play than did lower class children. Analyses of individual play components indicated that although middle class children verbalized more frequently, the quality of the language used by the two groups did not differ. Age differences were also significant. With age, play roles became more socially coordinated, the duration of play episodes increased and language became more complex. But social class groups did not differ on these measures. The implications of these results for the developmental lag hypothesis, other explanations of social class differences and classroom strategies are discussed.
\end{abstract}

\section{SOCIAL CLASS DIFFERENCES IN THE SOCIODRAMATIC PLAY OF PRESCHOOL CHILDREN}

According to several recent studies, make-believe activities may contribute to the social and intellectual functioning of preschool children (Rosen, 1974; Saltz \& Johnson, 1974; Saltz, Dixon, \& Johnson, 1977). Such make-believe play is limited in economically disadvantaged children (e.g., Feitelson \& Ross, 1973; Rosen, 1974; Smilansky, 1968; Smith \& Dodsworth, 1978), presumably because of the home environment in which these children are reared (Smilansky, 1968; Freyberg, 1973). Furthermore, when the fantasy and sociodramatic play of these children is enhanced through a variety of training procedures, their performance on a variety of social and intellectual tasks improves (Feitelson \& Ross, 1973; Saltz \& Johnson, 1974; Rosen, 1974; Saltz et al., 1977). Based on the above,

* Requests for reprints should be sent to Greta G. Fein, University of Michigan, School of Public Health, Ann Arbor, Mich. 48109. Work on this study was partially supported by a grant from The Spencer Foundation. 
investigators have offered the following conclusions: (a) the restricted play of disadvantaged children results from factors in the children's home environment, (b) this restriction reflects a problem in the functioning of symbolic processes, and (c) some form of play training may enhance play and improve symbolic functioning.

However, there are serious problems with several aspects of the evidence cited above. First, it is not clear whether the restricted play of disadvantaged children is a function of limitations in the children or limitations in the settings in which the children are observed. Indeed, the results of several studies indicate that make-believe play will vary as a function of the educational orientation of the program, teacher behavior, or location of play (e.g., Huston-Stein, Friedrich-Cofer, \& Sussman, 1977; Tizard, Philps, \& Plewis, 1976). The most influential study of play in children from different socioeconomic backgrounds was conducted by Smilansky (1968) who observed Israeli children in 36 different classrooms attended by either disadvantaged or advantaged children. These classrooms were segregated with respect to the socioeconomic backgrounds of the children (see also Rosen, 1974; Smith \& Dodsworth, 1978; Tizard et al., 1976). As a result, comparisons involved classrooms which might have offered different curricula and different supports or opportunities for sociodramatic play. Therefore, observed behavioral differences might reflect the situations in which the children were observed rather than the abilities of the children. In order to evaluate this possibility, it is necessary to examine the sociodramatic play of children from different backgrounds in the same classroom setting. Under these circumstances, social class effects are less easily attributed to differences in the physical setting, the curriculum, the teachers, or other classroom characteristics. One purpose of the present study was to examine the sociodramatic play of children from middle and lower class backgrounds attending the same preschool classrooms.

Second, studies of social class differences have used relatively global measures of sociodramatic play (Smilansky, 1968; Rosen, 1974; Rubin, Maioni \& Hornug, 1976). Although Smilansky discussed specific components of sociodramatic play at length, the measure used to compare social class groups was a global assessment of the presence or absence of play. As a result, little is known about the particular components of play that differentiate social class groups. The lack of evidence concerning specific play components makes it difficult to link social class differences to particular symbolic processes. It is therefore difficult to assess the outcomes of play training studies, especially since these studies report positive effects in a wide array of social and intellectual tasks. A second purpose of the present study was to examine the components of sociodramatic play that differentiate the play of middle and lower class children.

Finally, little is known about the way social class differences vary as a function of age. For example, Eifermann (1971) reported a reversal of social class differences in sociodramatic play for first and second grade children, 
suggesting a developmental lag in lower class children. A similar lag may be operating during the early years. There is evidence that between 3 and 6 years of age, peer interactions increase (Finkelstein, Dent, Gallagher, \& Ramey, 1978) and additional evidence that particular components of sociodramatic play also increase during these years (Garvey \& Berndt, 1977). It is possible then that social class differences appear on components of play associated with marked developmental changes. The relation between age and social class was, therefore, of considerable interest in the present study.

\section{METHOD}

\section{Subjects}

The children who participated in the present study were attending a YWCA sponsored day care center. The philosophy of the center might be described as a traditional nursery school (e.g., Tizard et al., 1976) with few teacher-directed or planned activities (e.g., Huston-Stein et al., 1976). The center accommodated approximately 95 children ranging in age from 3 to 6 years. A preliminary check of the registration records indicated that the children came from a range of social class backgrounds and that within each of the four classrooms, there was a balanced distribution of children with respect to social class. Two classrooms, each with two teachers, accommodated children who ranged in age from 3 to $4 \frac{1}{2}$ years, whereas the other two classrooms accommodated older children who ranged in age from $4 \frac{1}{2}$ to 6 years. Each classroom had its own similarly equipped play area; and, in addition, the children had access to two central common rooms in which they played at least once a day.

Information on the parents' occupation and education was used to divide the children into two social class groups. Children in the middle class group came from professional and managerial homes in which the mothers and/or fathers had received some cducation beyond high school, and were working or studying in a large university near the center. Children in the lower class group came from homes in which the mothers and/or fathers were less well educated, and were employed in semi-skilled or unskilled orcipations. Although more black than white children attended the center, there were children from each racial group within each social class category. Thus, it was possible to select for observation 24 children at each age level, 12 in each social class group, in such a way that racial composition was equivalent across age and social class groups. Unfortunately, most of the younger lower class children were boys. It was, therefore, not possible to construct groups with an equal numbers of boys and girls at the younger age level. In addition, three of the older boys were not in regular attendance during the observation period; their data were dropped from the final analyses. Observations of 45 children make up the present report. Twenty-one 
older children ranged in age from 5 to 6.5 years; 11 children ( 5 boys and 6 girls) were low in SES status, whereas 10 children (4 boys and 6 girls) were relatively high in SES status. The 24 younger children ranged in age from 3 to 4.5 years; 12 children ( 8 boys and 4 girls) were low in SES status, and 12 children ( 5 boys and 7 girls) were relatively high in SES status. At the time of the study, the mean duration of the children's attendance was four months. The older children had been in attendance somewhat longer than the younger children $(\mathrm{p}<.05)$.

\section{Procedures}

The observer, who was blind to the social class background of the children, spent the first week in the center informally observing the children and familiarizing them with the observational procedure. Over the next six weeks, observations of the children's make-believe play were made every school day during the freeplay period. The teachers interacted minimally with the children during these periods. 6 observations, each lasting 5 minutes, were made on each of the 45 children on six different days. Children were observed according to a prearranged schedule in which the observer rotated from classroom to classroom at the end of each five-minute observation, thereby increasing the variety of play likely to be sampled. During the first three observations, the observer did not initiate conversation with the children, responding briefly to their infrequent comments or inquiries. During the last three observations, the observer gently probed when pretend sequences were ambiguous (e.g., Where did the Daddy go?) Relatively few probes were initiated and preliminary analyses failed to reveal differences between the first and the last three observation periods. Data from the six observations were collapsed in subsequent analyses.

During the observations, components of sociodramatic play were recorded using a modified specimen format built around the components of play and verbal behavior described by Smilansky. For each five-minute observation period, the observer noted the scene being played, the child's actions and what they portrayed, the objects used and what they represented, play verbalizations, and instances of aggression (e.g., hitting, cursing, grabbing toys, name-calling). The duration of each scene was timed with a stop watch. The specimen records were subsequently coded according to the following make-believe elements: (a) self-referenced make-believe roles in which the child adopts a role (mother, father, doctor, animal, monster) without explicit verbal or nonverbal reference to a role played by another child, (b) other-referenced make-believe roles in which the child either suggests a role to another child or adopts a role suggested by another child in keeping with the scene being played, (c) make-believe scenes such as eating dinner, going on a picnic, birds in a nest, (d) make-believe use of objects, and (e) verbalization. Each of the first four make-believe elements were then rated on a three point scale according to the diversity and originality of the elements appearing in each five-minute episode. The diversity rating was based 
on the number of different self-referenced roles, other-referenced roles, and scenes and objects designated in the five-minute observation. Since a few children occasionally received high diversity scores on some elements, the frequency distribution of scores in the group, as a whole, was used to derive the three point scale in which scores of 0,1 , or 2 represented approximately the lowest, middle, or highest thirds of the distribution. The originality rating was based on whether or not the content of the particular element appeared on another five-minute record. An element was rated " 1 " if it appeared, and " 2 "' if it was unique. Play Verbalizations were scored according to the frequency and the mean length of the utterances. The number of utterances and mean length of the utterances produced by a child in each five-minute record were assigned a rating of $0,1,2$ according to the overall distribution of frequencies in the group. Each of the above scores was averaged over the six five -minute episodes, yielding for each child eight make-believe and two verbalization measures. In addition, each child received a persistence score (mean no. minutes per scene) and an aggression score (no. aggressive acts per episode) which were transformed to a threepoint scale in the manner described above. Two raters scored half of the 270 specimen records. The percentage of agreement (smaller score divided by the larger score) ranged from $85 \%$ to $96 \%$ on the 12 measures described above.

\section{RESULTS}

Preliminary correlational analyses revealed that play, language and persistence scores were highly intercorrelated. A composite Play Quality measure was therefore created by combining these scores. Table 1 gives the group means for the composite measure. An Age X SES analysis of variance performed on composite scores revealed a main effect for age $(F(1,41)=6.70, \mathrm{p}=.014)$ and a main effect for social class $(F(1,41)=4.86, P=.034)$. On the composite measure, older children scored higher than younger children, and middle class children scored higher than lower class children. These latter findings are in accord with those reported by Smilansky (1968) and Rosen (1974) using somewhat different measures of the overall level of sociodramatic play. The age by social class interaction was not significant, indicating that social class differences did not vary as a function of age.

TABLE 1

Means for Composite Sociodramatic Play Measure for Age and Social Class Groups

\begin{tabular}{ccc} 
Age & Middle Class & Lower Class \\
Group & & \\
\hline Younger $(3-4 \mathrm{~T} / 2)$ & 7.16 & 5.39 \\
Older $(4 \mathrm{l} / 2-6)$ & 8.77 & 7.43 \\
\hline
\end{tabular}


A second series of analyses were performed on the scores for elements of make-believe, verbalization frequency, MLU, persistence and aggression. In order to better represent the flavor of the play, raw scores (averaged over the six five-minute observations) were used in the analysis, with one exception. The distribution of verbalization frequency was so markedly skewed that the score derived from the procedure described earlier was used. Children received a verbalization frequency score of 0,1 , or 2 depending on whether the child's raw score fell on the first, second or third tertile of the frequency distribution.

TABLE 2

Age Effects for Play Diversity, Persistence and Aggression'

\begin{tabular}{|c|c|c|c|}
\hline Play Component & $\begin{array}{l}\text { Younger } \\
(3-41 / 2)\end{array}$ & $\begin{array}{c}\text { Older } \\
(41 / 2-6)\end{array}$ & F-ratio ${ }^{1}$ \\
\hline Self-referenced roles & 2.80 & 2.77 & ns \\
\hline Other referenced roles & 2.41 & 3.67 & $6.76^{* *}$ \\
\hline Make-believe scenes & 3.41 & 3.21 & ns \\
\hline Make-believe objects & 8.03 & 7.93 & ns \\
\hline Verbal frequency & 1.01 & 1.57 & $19.61 * * *$ \\
\hline MLU & 1.69 & 2.28 & $4.67^{\star}$ \\
\hline Persistence & 2.70 & 3.61 & $8.78^{* *}$ \\
\hline Aggression & .31 & .85 & \\
\hline $\begin{array}{l}{ }^{\star} p \leqslant .05 \\
{ }^{\star \star} p \leqslant .01 \\
{ }^{\star \star *} p \leqslant .001 \\
{ }^{1} d f=1 / 41\end{array}$ & & & \\
\hline
\end{tabular}

Table 2 gives the means and $F$-ratios for younger and older groups on the diversity of self- and other referenced roles, make-believe scenes and objects, verbal frequency, MLU, persistence and aggression. Since the results were similar for diversity and originality scores and the two were highly correlated ( $r$ $=.89$ or better), only the former are shown. Age differences were not significant for the diversity of self-referenced roles, scenes and make-believe objects, and elements of make-believe that might be viewed as the core of dramatic play (Fein \& Apfel, 1979). Age differences were significant on the element of makebelieve play that most reflects the children's social interactive skills. Older children were more likely than younger children to synchronize the roles they adopted with the roles adopted by others. For example, in the play of older children, the role of nurse was more likely to be coordinated with the roles of patient, doctor, or ambulance driver played by others. This coordination appeared in both the diversity and originality of other-referenced roles. Significant age differences also appeared in the verbal component of sociodramatic play. Older children were more likely than younger children to talk about the roles, objects, scenes and events represented in the play, and they were also more 
likely to talk in the manner of the roles being enacted. The older children also produced longer and, presumably, more complex utterances. The scenes played out by the older children were also of longer duration. Finally, although non-play acts of aggression occurred infrequently, older children were more likely than younger children to engage in such behavior.

If social class differences reflect a developmental lag on the composite measure, the analyses of individual play components would be expected to reveal a pattern of social class differences similar to that found in the analysis of age differences. Such was not the case. Social class differences appeared on only one measure, that of verbalization frequency $(F(1.41)=4.35, p=.042)$. Middle class children $(M=1.43)$ produced more play verbalizations than did lower class children $(M=1.16)$. However, the quality or complexity of the language spoken by the two groups did not differ significantly. Possibly, then, the difference between social class groups that appeared on the composite measure was due to the contribution of verbalization frequency. In order to examine this possibility, verbal frequency was deleted from the composite measure, and an analysis of variance was performed on the new score. Significant age $(F(1.41)=4.32, p=$ $.044)$ and social class $(F(1.41)=4.52, p=.042)$ differences remained, and the interaction was not significant. In general, differences on the individual measures favored middle class children; but, these differences were not substantial enough to reach accepted levels of significance.

\section{DISCUSSION}

Although children share the same physical space, have access to the same materials and, presumably, have access to one another, they do not necessarily share the same interests or participate in the same activities in the same way. When children from different social class backgrounds are observed in the same classrooms, middle class children show higher levels of play than do lower class children, at least on a composite measure of play. However, the difference found in the present study is modest, compared to that reported by other investigators. For example, Smilansky (1968) reported that while $69 \%$ of the disadvantaged children were not engaged in any pretense, only $3 \%$ of the advantaged children were also not involved. This difference is considerably greater than that reported by Smith and Dodsworth (1978) for English children (37\% and 13\%, respectively). In the present study, every child was engaged in pretense at least once, regardless of social class.

The findings of social class differences must be evaluated with reference to the growing evidence that children's play is influenced by setting factors, such as location (e.g., indoors versus outdoors), school curriculum or teacher training (e.g. , Huston-Stein et al., 1977; Smith \& Dodsworth, 1978; Tizard et al., 1976). Settings that enhance the pretend play of lower class children (e.g., outdoors) may 
inhibit that of middle class children (Tizard et al., 1976). For each group, there may be a particular set of conditions under which play is optimized. Conceivably, if lower class children were observed under optimizing conditions and middle class children under inhibiting conditions, the direction of the differences might be reversed.

These possibilities bear upon the heatedly debated issue of how differences associated with class or ethnicity are to be interpreted (Schwartzman, 1978; Sutton-Smith, 1980). On the one side are those who view these differences as a function of cognitive deficits in the child (Smilansky, 1968), a view echoed in recent play-training studies with American disadvantaged children (e.g., Freyberg, 1973; Rosen, 1974; Saltz et al., 1977). This view produced the developmental lag hypothesis which implies that social class groups will differ on those aspects of play associated with advanced developmental status (Eifermann, 1971). Although this hypothesis was initially offered as a post hoc explanation of findings that have been recently contested (Feitelson, 1979), it nevertheless merits serious attention. The present study was designed to examine whether social class differences reflect differences in the cognitive or symbolic maturity of the children.

On the composite measure of play, older children achieved higher scores than younger children. When age differences on individual measures were examined, older children surpassed younger children on those measures identified by other investigators as indicative of developmental maturity during the preschool years (see Fein, 1981, for a review of this literature). Five year olds were more likely than four year olds to develop reciprocal roles, to sustain pretend enactments, and to produce more complex language. Age differences did not appear on those aspects of pretense (e.g., self-referenced roles, make-believe scenes, and objects) that are well established by four years of age.

However, these age sensitive measures did not differentiate middle from lower class children; i.e., middle class children did not surpass lower class children on measures of advanced developmental status, nor did lower class children surpass middle class children on measures of less advanced status. The groups differed significantly only on one individual measure, the amount of language produced. In effect, social class differences on the composite measure resulted from small, cumulative, and non-significant differences on individual measures. The composite score may thereby assess a dimension of individual difference other than developmental status. This possibility supports the position of those who argue that a deficit interpretation of social class differences is premature, and that other plausible explanations merit attention (e.g., Schwartzman, 1978; Fein, 1981). Before discussing two alternatives to the deficit view, some methodological observations are in order.

Until recently, psychologists have paid little attention to the distinction between "typical" and "best" performance. The former refers to the type of behavior that occurs most frequently when the relative frequency of different 
behaviors is of interest. If a variety of settings were evaluated with respect to their availability as play environments for children from different social class groups, one could construct a set of histograms describing variations in typical behavior as a function of the availability (or typicality) of settings. The exercise would yield information about the distribution of a behavior, such as pretense, in relation to the distribution of settings. One might then designate some settings as optimal for one group and other settings as optimal for the other, based simply on a judgment of where the target behavior (e.g., pretense) is most likely to occur for each group. There may, in fact, be fewer settings in which lower class children exhibit their best performance, and when behavioral frequencies are summed over situations, the results may indicate that middle class children typically pretend more than lower class children. If so, one might conclude that lower class children have fewer opportunities to perform behavior that they are quite capable of performing. Therefore, the problem becomes one of opportunity rather than competence.

One might also impose upon this analysis a theoretical model of competence in which behaviors are assessed according to their position in an explicit developmental progression. Of interest in such an analysis need not be the frequency of a behavior category but whether or not it occurred. Then, if a variety of settings were sampled, the analysis will pertain to variations in the children's highest level of performance under a variety of conditions. It will yield information about the settings which evoke mature behavior.

A concept of the "highest level"' under "optimum" conditions may be especially appropriate in the study of pretend play. For example, one of the older children in the present study initiated a game in which he was a human-vampirebat planning to devour a newborn bird that the father bird was protecting. The child not only developed the role with great subtlety, but also turned to an imaginary audience with occasional asides aimed at revealing how the villainous plot was to unfold. In a developmental scheme far more refined than the one used here, behavior which seemingly involves the deliberate embedding of play within a play might be credited as an especially sophisticated achievement. Unfortunately, there have been few attempts to develop and validate sequential models of the development of pretend play, and these attempts have focused on the solitary pretense of infants (e.g., Nicolich, 1977; Watson \& Fischer, 1977).

Given the above, at least two additional explanations of social class effects merit scrutiny. According to one, parents differ in their views of where children ought to play. In some families, outdoors is for play; houses are for eating, sleeping, and quiet, orderly activities. There is some evidence that this view is more likely to appear in lower rather than middle class families and that lower class children locate their play according to their parents' preferences (e.g., Tizard et al., 1976; Wootton, 1974). For such children, the preschool classroom may be an inappropriate context for assessing play competence since socialization factors work against the expression of such competence. If these children 
were observed in a context congruent with their social training (e.g., outdoors), play levels might be elevated. A similar analysis might be applied to middle class children who, when observed in a context incongrucnt with their social training, might show depressed levels of play.

The context-socialization hypothesis thus leads to the prediction that under some circumstances, social class and play context might interact. Of course, a variety of school, neighborhood, home and laboratory contexts need to be studied to flesh out the influence of context on either the typical or best performance. However, the results will only be interpretable if the distinction between opportunity and competence is respected.

According to a second hypothesis, social class differences are primarily a function of the emotional uncertainty or apprehension that lower class children experience in an unfamiliar classroom setting. First, there is ample evidence that emotional stress suppresses play and that novel environments have a similar effect (e.g., Fein, 1981). Second, lower class homes are less likely to provide children with the rich array of play materials found in middle class homes or preschool classrooms, and lower class children are more likely to experience adults as negative sources of authority (Dunn \& Wooding, 1977; Wootton, 1974). Given these experiential differences, lower class children in a school setting may be more likely than middle class children to engage in exploratory, functional behaviors, at least until the setting has become familiar and the role of the teacher clarified. Limited evidence is consistent with this notion (e.g., Rubin et al., 1976; Tizard et al., 1976). The emotional arousal hypothesis calls for longitudinal studies in which children are observed over time in a socially integrated classroom setting, or for interventions in which an effort is made to prefamiliarize lower class children with materials and teachers. It should be noted, however, that according to the present study, more than four or five months of familiarization might be required for such emotional factors to subside. Context and arousal hypotheses might be studied concurrently if play behavior in contexts that were congruent and incongruent with social training were studied over time (e.g., Fein, 1975).

Findings of the present study and motivational explanations of social class differences have several implications for the interpretation of play training studies and for the development of classroom strategies for the enhancement of play. With respect to play training studies, it is notable that significant improvement in the pretend play of lower class children can occur with as few as eight 20 minute sessions of interaction with a friendly, play encouraging adult (e.g., Freyberg, 1973). The speed and ease with which play can be enhanced is more in keeping with the interpretation of social class differences as a motivational difference than as a cognitive deficit. If this interpretation has merit, the long, intensive training sessions used by other investigators (e.g., Rosen, 1974; Saltz \& Johnson, 1974; Saltz et al., 1977) may be unnecessary. Teachers who believe that pretend play in the classroom will enhance children's development might be 
better advised to plan "encouragement" sessions for those children who seem reluctant to engage in such play than to develop extensive "how to play" curricula. Other procedures designed to convince children that such play is appropriate in the classroom setting or to familiarize children with classroom materials might also be effective. If outdoors is preferred by lower class children, outdoor play spaces might be designed or equipped with pretend play in mind.

Although, as discussed earlier, longitudinal studies are needed to clarify major issucs concerning the durability of social class differences in integrated classroom settings, middle and lower class children in the present study had spent a substantial amount of time together. The data suggests that peers who engage in sociodramatic play do not necessarily encourage this play in others (Rubin et al., 1976). Informal examination of the specimen records indicates that lower class children who try to participate are not rejected by their peers. Rather, lower class children often play on the periphery of an active group, imitating others but not becoming central participants. Mechanisms such as peer modeling or peer interaction may simply not be strong enough to overcome factors such as the preoccupation of central players in their pretend games and the hesitation of peripheral children to share this preoccupation. Children may provide one another with comfort or important information about the environment, but skillful teacher interventions may be needed to realize this potential.

Limitations of the present study must be noted. First, although children were observed in four classrooms, only one center was studied. The program philosophy of the center stressed free play with minimal teacher intervention. Since early childhood programs vary in the degree to which make-believe play and peer interaction are encouraged, settings that vary in program philosophy need to be studied in order to examine the conditions under which social integrated settings might promote play between children from different social class backgrounds. Second, the range of social class differences in the present study was limited. However, integrated settings attended by children of widely varying social class backgrounds are uncommon, and when available, often reflect special circumstances likely to make the findings difficult to interpret. Since social class differences appeared in the present study with a relatively restricted social class range, it might be fruitful to compare integrated and segregated classrooms attended by children from different social class backgrounds. Social class differences may be muted in integrated, relative to segregated settings. This is a possibility that the present study was unable to examine. Finally, children in the present study were not observed when school attendance first began, nor were group participation strategies systematically studied. A longitudinal research design spanning several months might be needed to trace changes in the social interaction and play of lower class children attending integrated preschool settings.

Social class differences in children's play may be easier to find than explain. However, strategies for enhancing play reflect a diagnosis of what sup- 
presses it. Results of the present study fail to confirm the notion that lower class children are developmentally less mature than middle class children. But other hypotheses merit systematic scrutiny. A sound diagnosis may yield more effective and efficient ameliorative strategies than a mistaken one.

\section{REFERENCES}

Dunn, J., \& Wooding, C. Play in the home and its implications for learning. Biology of play. London: William Heineman, 1977.

Eifermann, R. R. Social play in childhood. In R. E. Herron, \& B. Sutton-Smith (Eds.), Child's play. New York: John Wiley \& Sons., 1977

Fein, G. G., \& Apfel, N. Some preliminary observations on knowing and pretending. In N. Smith, \& M. B. Franklin (Eds.), Symbolic Functioning in Childhood, New York: Erlbaum, 1979.

Fein, G. G., \& Moorin, E. R. Confusion, substitution and mastery. In K. Nelson (Ed.), Children's Language (Vol. 5). New York: Gardner Press, 1981.

Fein, G. G. Pretend play: An integrative review. Child Development, in press, 1981.

Fein, G. G. Children's sensitivity to social contexts at 18 months of age. Developmental Psychology, $1975,11,527-528$.

Feitelson, D. Imaginative play and the education process. Paper presented at the International Year of the Child Conference, New Haven, 1979.

Feitelson, D., \& Ross, G. S. The neglected factor-Play. Human Development, 1973, 16, 202-223.

Finkelstein, N. W., Dent, C., Gallagher, K., \& Ramey, C. T. Social behavior of infants and toddlers in a day care environment. Developmental Psychology, 1978, 14, 257-262.

Freyberg, J. T. Increasing the imaginative play of urban disadvantaged kindergarten children through systematic training. In J. L. Singer, (Ed.), The child's world of make-believe. New York: Academic Press, 1973.

Garvey, K., \& Berndt, R. Organization of pretend play. Catalogue of Selected Documents in Psychology, 1977, 7 (No. 1589), American Psychological Association.

Huston-Stein, A., Friedrich-Cofer, L., \& Sussman, E. J. The relation of classroom structure to social behavior, imaginative play, and self-regulation of economically disadvantaged children. Child Development, 1977, 48, 906-916.

Nicolich, L. M. Beyond sensorimotor intelligence: Assessment of symbolic maturity through analysis of pretend play. Merrill-Palmer Quarterly, 1977, 23, 89-99.

Rosen, C. E. The effects of sociodramatic play on problem-solving behavior among culturally disadvantaged preschool children. Child Development, 1974, 45, 920-927.

Rubin, K. H., Maioni, T. L., \& Hornug, M. Free play behaviors and lower-class preschoolers: Parten and Piaget revisited. Child Development, 1976, 47, 414-419.

Saltz, E., Dixon, D., \& Johnson, J. Training disadvantaged preschoolers on various fantasy activities: Effects on cognitive functioning and impulse control. Child Development, 1977, 43, $367-380$.

Saltz, E., \& Johnson, J. Training for thematic-fantasy play in culturally disadvantaged children: Preliminary results. Journal of Educational Psychology, 1974, 66, 623-630.

Schwartzman, H. B. Transformations: The anthropology of children's play. New York: Plenum, 1978.

Smilansky, S. The effects of sociodramatic play on disadvantaged preschool children. New York: Wiley, 1968.

Smith, P. K. \& Dodsworth, C. Social class differences in the fantasy play of preschool children. Journal of Genetic Psychology, 1978, 133, 183-190. 
Sutton-Smith, B. Expressive styles in fantasy play. Paper presented at the meetings of the American Psychological Association, Montreal, Canada, September 1980.

Tizard, B., Phelps, J., \& Plewis, J. Play in preschool centers-II. Effects on play of the child's social class and of the educational orientation of the centre. Journal of Child Psychology and Psychiatry, 1976, 17, 265-274.

Watson, M. W., \& Fischer, K. W. A developmental sequence of agent use in late infancy. Child Development, 1977, 48, 828-836.

Wootton, A. J. Talk in the homes of young children. Sociology, 1974, 277-295. 